\section{Measurement of Elastic Modulus and Vickers Hardness of Surround Bone Implant Using Dynamic Microindentation - Parameters Definition}

Priscilla Barbosa Ferreira Soares ${ }^{1}$, Sarah Arantes Nunes ${ }^{2}$, Sinésio Domingues Franco ${ }^{3}$, Raphael Rezende Pires ${ }^{3}$, Darceny Zanetta-Barbosa², Carlos José Soares $^{4}$

The clinical performance of dental implants is strongly defined by biomechanical principles. The aim of this study was to quantify the Vicker's hardness (VHN) and elastic modulus (E) surround bone to dental implant in different regions, and to discuss the parameters of dynamic microindantion test. Ten cylindrical implants with morse taper interface (Titamax CM, Neodent; $3.5 \mathrm{~mm}$ diameter and $7 \mathrm{~mm}$ a height) were inserted in rabbit tibia. The mechanical properties were analyzed using microhardness dynamic indenter with $200 \mathrm{mN}$ load and $15 \mathrm{~s}$ penetration time. Seven continuous indentations were made distancing $0.08 \mathrm{~mm}$ between each other perpendicularly to the implant-bone interface towards the external surface, at the limit of low (Lp) and high implant profile (Hp). Data were analyzed by Student's t-test ( $\alpha=0.05$ ) to compare the $E$ and VHN values obtained on both regions. Mean and standard deviation of $\mathrm{E}(\mathrm{GPa})$ were: Lp. $16.6 \pm 1.7$, Hp. 17.0 \pm 2.5 and VHN (N/mm²): Lp. $12.6 \pm 40.8$, Hp. $120.1 \pm 43.7$. No statistical difference was found between bone mechanical properties of high and low profile of the surround bone to implant, demonstrating that the bone characterization homogeneously is pertinent. Dynamic microindantion method proved to be highly useful in the characterization of the individual peri-implant bone tissue.
'Department of Periodontology and Implantology, UFU - Federal University of Uberlandia, Uberlândia, MG, Brazil ${ }^{2}$ Department of Oral and Maxillofacial Surgery and Implantology, UFU Federal University of Uberlandia, Uberlândia, MG, Brazil

${ }^{3}$ Department of Mechanical Engineering, UFU - Federal University of Uberlandia, Uberlândia, MG, Brazil ${ }^{4}$ Department of Operative Dentistry and Dental Materials, UFU Federal University of Uberlandia, Uberlândia, MG, Brazil

Correspondence: Prof. Dr. Carlos José Soares - Avenida República do Piratini, $\mathrm{S} / \mathrm{N}$, Campus Umuarama, Bloco 4LA, Sala 4LA32, Uberlândia, Minas Gerais 38405-325, Brasil. e-mail: carlosjsoares@umuarama.ufu.br

Key Words: bone, dental implant, elastic modulus, Vickers hardness, dynamic microindentation.

\section{Introduction}

The primary function of the stomatognathic system is preparation and processing of food through a biomechanical process of biting and chewing $(1,2)$. This mechanism is based on the transfer of masticatory forces, mediated through the implant or intact and restored teeth. The integration between implant and bone depends on the tissue quality, and the inductive bone growing potential of the implant surface $(2,3)$. The interactivity between the implant and surrounding bone is a typical repair process affected by the intensity and direction of the load applied over implant (4). The interface between bone and implant should be biologically integrated creating a unique body that is able to absorb the stress-strain generated by masticatory force (5). Titanium alloys have been extensively used as biomaterials in dental implantology due to their good mechanical performance and biocompatibility. Surface implant modifications using physical and chemical treatments have been used to increase the bone interaction to implants. $(3,6)$.

Bone is a structure composites of an organic matrix (organized network of type I collagen fibrils) filled with a mineral component (apatite crystals bound to the collagen fibrils) $(7,8)$. Trabecular bone has a porous structure and is located in medullary cavities $(9,10)$. The effect of the implant parameters, bone quality and characteristic modulated by different aspects like aging, irradiation, tobaccoism, coffee consumption and alcohol consume, have been evaluated using several laboratory techniques $(4,10-12)$. From a macro-biomechanical perspective, the anchorage of implants has been assessed using tensile tests (13), torque (14), pull-out (2) and push-in tests (2). Regarding micromechanical integration, the mechanical properties of surround bone to titanium implants have been evaluated using microindentation $(4,15)$. Microindentation is a dynamic method that allows the determination of both the elastic modulus and the hardness of bone in the bone-implant interface, taking into account the anisotropic condition of the tissue structure $(4,10,15,16)$.

The use of animal models has been useful to compare the treatment and to better explain the bone alterationintegration process (2). The advantage of the rabbit model is that it is a small animal and can accept dental implants in long bones, as the tibia and the femur $(2,14)$. The reproducibility of animal model used is an important factor on the extrapolation of the results obtained for 
human health. Hansma et al. (17) related that have no instrument that can clinically measure the properties of bone in vivo. Additionally, the possibility to obtain the specific mechanical properties for each animal after euthanasia using microindentation may contribute for generation of the specific computational analysis of the influence the bone quality on the stress distribution using finite element models $(18,19)$.

Limited description in the literature, to the best of our knowledge, of the parameters used to calculate the microindentation for animal samples has been described. $(4,10,15-17,20)$ Therefore, using dynamic microindentation this study aimed: 1) to calculate the mechanical properties (elastic modulus and Vicker hardness) of the surround bone to dental implant immediately after insertion into the rabbit tibia; 2 ) to verify the influence of the implant-bone region on the bone mechanical properties.

\section{Material and Methods}

The research project was approved by the Ethics Committee of the Federal University of Uberlândia (Protocol \#093/12). Five rabbit tibias were used. The residual soft tissue was removed and the tibias were stored in phosphatewere removed from the frozen and stored on the bench for $2 \mathrm{~h}$ into the phosphate-buffered saline solution (21). 2:

\section{Sample Preparation}

Two implants (3.5-mm diameter, 7.0-mm long dental implants; Titamax CM; Neodent, Curitiba, PR, Brazil) were inserted in the tibia diaphysis, with a distance of $10 \mathrm{~mm}$ from each other. The implants were inserted following the manufacturer's recommendation. The holes for the installation will be performed with 20:1 handpiece (Gearbox NSK E16R, Nakanishi, Shimohinata, Japan), mounted on electric motor (DrillerSmart, MIS Implant Technologies, Shlomi, Israel), with $800 \mathrm{rpm}$ under copious irrigation with $0.9 \%$ saline solution. The tibia with two implants was sectioned using a water-cooled double-faced high-speed diamond disc longitudinally, reaching the center of the each implant and $5 \mathrm{~mm}$ from the other external limit of the implant, creating 2 samples for each tibia. The tibia was longitudinally sectioned reaching implant (Fig. 1A) using a precision saw (Isomet 1000, Buehler, Lake Bluff, IL, USA). The block consisted of the bone-implant sample was embedded using polyester resin (Instrumental Instrumentos de Medição Ltda, São Paulo, SP, Brazil). To perform the embedment process, the sample was positioned with the cutting implant surface downward over a glass plate and fixed using adhesive (Single Bond 2; 3M-Espe, St. Paul, MN, USA). The adhesive system was applied in a thin layer and the sample was stabilized using digital pressure followed by light activation for $20 \mathrm{~s}$ (Demetron; Kerr, Orange, CA, USA). A metallic tube (Metalon; Metalon Pooled Industries, Nova Iguaçu, RJ, Brazil) with $50 \mathrm{~mm}$ in length $30 \mathrm{~mm}$ in width and $10 \mathrm{~mm}$ in high was positioned around the sample and was fixed with wax. Three samples were embedded per block (Fig. 1B).

An important aspect that influenced on the methodology reproducibility was the position of the cutting performed on the implant-bone sample. During pilot study initially the cutting performed using precision saw was done into the center of the implant. During the finishing and polishing of the sample, several implants detached to the bone compromising the sample. Then, the position was modified by moving no more than 1.0 $\mathrm{mm}$ laterally to the center of the implant and the sample used to finish and polish was the side where is located the bigger amount of the implant. Therefore, when the finish and polish was finalized, the amount of the implant was sufficient to maintain the implant the correct position. After curing of the polyester resin, the surfaces were finished using 600-, 800-, 1200- and 2000-grit silicon-carbide papers (Norton, Campinas, SP, Brazil) and polished with metallographic diamond pastes $(6,3,1,1 / 4 \mu \mathrm{m}$; Arotec, São Paulo, SP, Brazil). The metallic tube-implant was washed in an ultrasound bath (Cristofoli, Campo Mourão, PR, Brazil) with absolute alcohol for 3 times of 7 minutes each one to remove the debris.
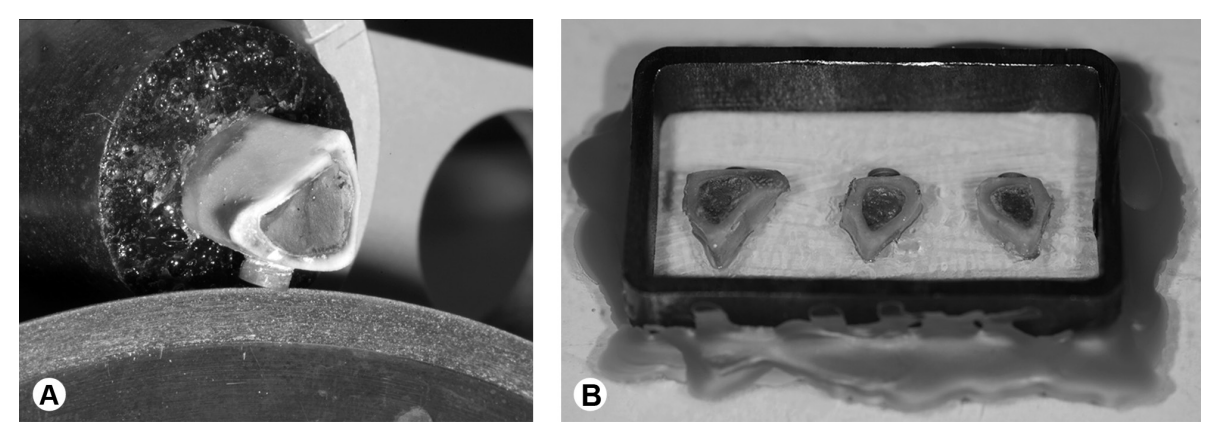

Figure 1. A. Cutting process of bone-implant preparation; B. Samples into the metallic tube fixed with wax. 


\section{Dynamic Indentation Test}

Elastic modulus (E) and Vickers Hardness (VHN) of the bone was assessed by using a microhardness dynamic indenter (CSM Micro-Hardness Tester; CSM Instruments, Peseux, Switzerland). Seven continuous indentations were made distancing $0.08 \mathrm{~mm}$ between each other perpendicularly to the implant-bone interface towards the external surface, considering the low and high profiles. The test load was increased and decreased at a constant speed between 0 and $200 \mathrm{mN}$. The force increased from 0 to 200 $\mathrm{mN}$ in $60 \mathrm{~s}$ intervals, which was applied constantly for 15 s. Then the force was gradually removed from $200 \mathrm{mN}$ to $0 \mathrm{mN}$ in $60 \mathrm{~s}$ intervals. The load and the penetration depth of the indenter were continuously measured during the load-unload-hysteresis (22). The hardness is defined as the test force divided by the apparent area of the indentation at maximal force. From a multiplicity of measurements stored in a database supplied by the manufacturer, a conversion factor between hardness and VHN was calculated and implemented into the software, so that the measurements were expressed in Vickers hardness units:

$$
V H N=\frac{P}{A}
$$

where: $P$ is the maximum load, $A$ is the deep-sensing instrument.

The indentation modulus was calculated from the slope of the tangent of the indentation depth-curve at maximal force (Fig. 2) and is comparable with the elastic modulus of the material $(E)$ expressed and using this formula:

$$
E=\frac{1-v_{s}^{2}}{\frac{1}{E_{r}}-\frac{1-v_{i}^{2}}{E_{i}}}
$$

where: $E i$ is the elastic modulus of the diamond indenter $(1141 \mathrm{GPa})$, $v$ i is the Poisson's ratio of the diamond indenter (0.07), Er is the reduced modulus of the indentation contact, and $v s$ is the Poisson's ratio of the bone (0.3) (20). The typical course of measurement curve is shown in Figure 2.

Table 1. Mean and standard deviation of Elastic modulus (GPa) and Vickers Hardness ( $\mathrm{N} / \mathrm{mm} 2)$ of low and high profile of surrounding bone to dental implant

\begin{tabular}{lcc}
\hline \multirow{2}{*}{ Mechanical properties } & \multicolumn{2}{c}{$\begin{array}{c}\text { Measurement location bone/ } \\
\text { implant interface }\end{array}$} \\
\cline { 2 - 3 } & Low profile & High profile \\
\hline Elastic modulus $(\mathrm{GPa})$ & $16.6 \pm 1.7^{\mathrm{A}}$ & $17.0 \pm 2.5^{\mathrm{A}}$ \\
Vickers hardness $\left(\mathrm{N} / \mathrm{mm}^{2}\right)$ & $125.6 \pm 40.8^{\mathrm{A}}$ & $120.1 \pm 43.7^{\mathrm{A}}$ \\
\hline
\end{tabular}

Letters represent statistical category within each mechanical property as a function of location around the steps of implant thread, defined by t-Student test $(\mathrm{P}<0,05)$ for each mechanical property.

\section{Statistical Analysis}

The $\mathrm{E}$ and $\mathrm{VH}$ data were tested for normal distribution (Shapiro-Wilk, $p>0.05$ ) and equality of variances (Levene's test, $p>0.05)$, followed by parametric statistical tests. The pared $t$-Student test was performed the comparison between the data recorded in each bone region (low and high profiles). All tests employed a 0.05 level of statistical significance and all statistical analyses were carried out with the statistical package Sigma Plot version 13.1 (Systat Software, Inc., San Jose, CA 95110 USA).

\section{Results}

The $\mathrm{E}$ values in $\mathrm{GPa}$ for the bone structure in low and high profiles of implant interface are shown in Table 1. The t-Student test showed no difference between $E$ recorded at low and high profile regions ( $P=0.663$ ). The $E$ values recorded at different distance of the implant interface were plotted in Fig 3. The E values at all distances maintained stable irrespective of bone region.

The Vickers hardness in VHN for the bone structure in low and high profiles of implant interface are shown in Table 1. The Student's t-test showed no difference between $E$ recorded at low and high profile regions $(p=0.777)$. The VHN values recorded at different distance of the implant interface are plotted in Figure 4. The VHN values at all distance maintained stable irrespective of bone region.

\section{Discussion}

In order understand the mechanical properties and the mechanisms involved in bone fragility, it is important to study the mechanical properties of its different components, and the relationships between them at the various levels of the structural organization $(7,10)$. The dynamic indentation method described in this study showed very effective to

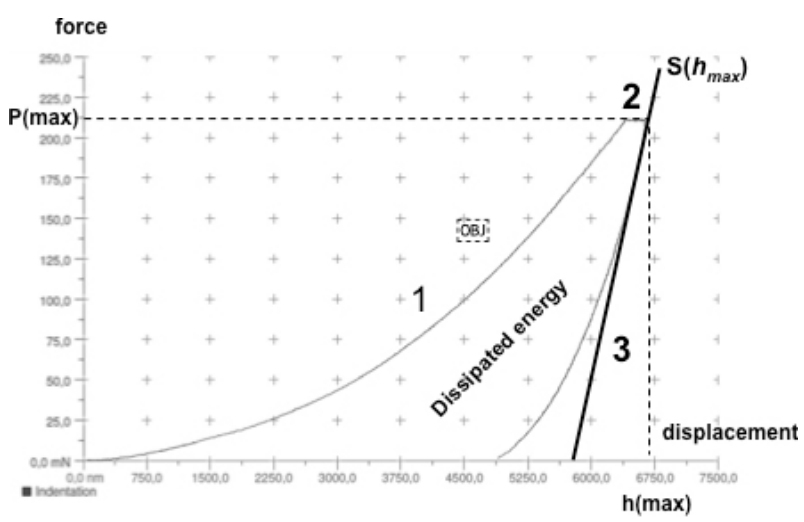

Figure 2. Force-displacement curve of a microindentation test: loading (1), holding (2), unloading (3) of an indenter tip. The third part leads to elastic recovery of the material and its initial slope is used to derive the elastic indentation modulus. The hysteresis represents the dissipated energy. 
determine both important mechanical properties ( $E$ and VHN). The low variability of the data acquisition and the easy reproducibility of this methodology confirmed the validity of this method to study the bone/implant interaction.

The ratio between stress and strain that is resulted into the body in order to the force applied externally characterizes the elastic modulus of the structure. The modulus of elasticity of a material represents its stiffness and for most materials remains constant over a range of stress. The ratio of the longitudinal strain to the longitudinal stress in the linear part of the curve called Elastic modulus $(15,17,20)$. The bone integrity around the implant may be inferred by the constant elastic modulus measured by indentation method in different regions.

The elastic modulus of bone and hardness represents and is greatly influenced by the proportion of the anisotropic type I collagen fiber and the hydroxyapatite crystal composite $(7,8)$. According to Rho et al. (7) and Leng et al. (8), the differences in elastic modulus have been speculated to be in close relation to the turnover of the bone, ie, the maturity of the individual osteons, moreover, the distribution of their types. In general, it has been suggested that in the bone, the elastic modulus correlates with hardness $(4,9,10)$.

The elastic modulus reduction of the surround bone to implant has been correlated to the poor bone integration of the dental implant $(2,15)$. In the present study was analyzed the $E$ and VHN on low and high profiles of the surround bone aiming to test the immediate negative effect caused by specific drills used during hole implant preparation. The last drill used during whole preparation has $2.8 \mathrm{~mm}$ in diameter and the implant has $3.5 \mathrm{~mm}$ in diameter. Thus, the stress caused by implant insertion may cause damage on the area due to the high profile of the bone $(2,15)$. However, no significant difference was found between low and high profile regions, and then it can be speculate that no damage was caused by this procedure.

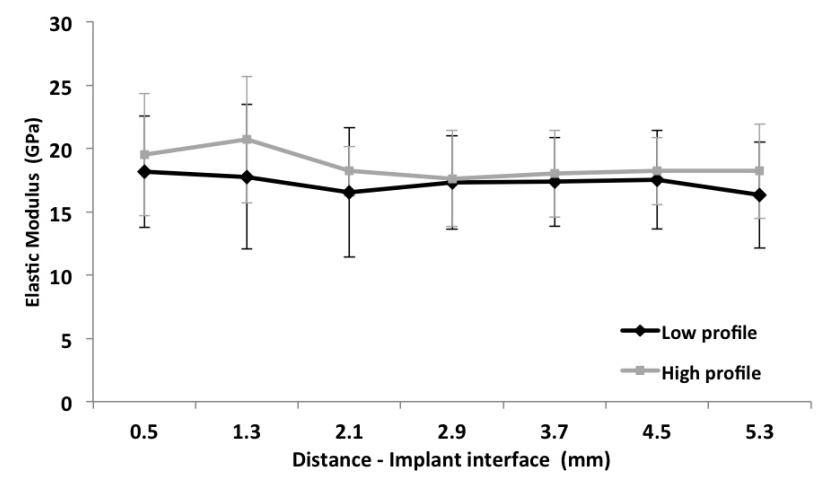

Figure 3. Elastic modulus bone values for all distances measured at low and high implant profiles.
Indentation techniques have been widely used to study bone tissue micromechanical properties $(4,9,10,15,16,20)$. However, interpreting microhardness values is complicated because this parameter is related to both elastic and plastic deformations $(4,9,10,15,20)$. Hansma et al. (17) developed an innovative technique to measure directly, on small indented areas, both elastic modulus (E) and contact hardness $(\mathrm{Hc})$. Contact hardness corresponds to the ratio between indentation load and the contact area of the indentation print. Elastic modulus was calculated from the slope of the tangent of the indentation depth-curve at maximal force and is comparable with the elastic modulus of the material $(\mathrm{E})$, which this method the calculation take into account more realistic the viscoelasticity of the bone tissue.

The second purpose of this study was to better establish the parameters of this methodology for testing the $E$ and VHN for rabbit tibia used to test dental implant model. This experimental method involved the frozen bone stored for $24 \mathrm{~h}$, however the frozen storage bone containing implants at $-20^{\circ} \mathrm{C}$ has no effects on the biomechanical properties of Bone/ Implant interface (23). During pilot study were performed different methods to embed the bone-implant sample into polystyrene resin. The use of the metallic tube to embed the sample is mandatory to result in better flattening of samples during finishing and polishing procedures (18). When the samples were embedded only into polystyrene resin, during the finishing procedure the surface is not flat because no stronger material can limit the finishing process. During the indentation test, firstly is performed a reference indentation to determine the distance of the surface to the indenter $(2,18)$. When the surface is not real flat the equipment is not able to perform the second indentation and the test consumed much more time and the data recorded resulting in high variability.

Elastic modulus and Vickers hardness of the rabbit

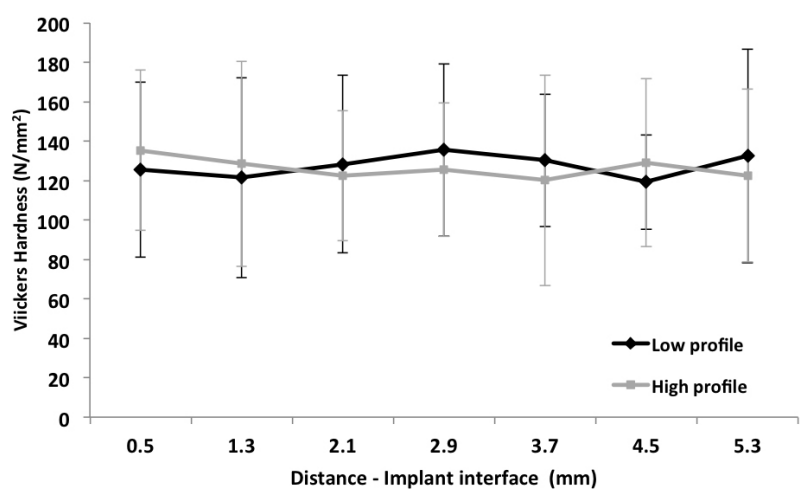

Figure 4. Vickers hardness bone values for all distances measured at low and high implant profiles. 
bone is very similar to human bone and the cost of the experiment is much lower than for dog experiments. Posterior maxilla is very important region for implant strategy for oral rehabilitation, the possibility to find an animal model with bone characteristic similar is very important for research field. Seong et al. (1) calculate the elastic modulus of posterior human maxilla bone and found results that range from 13.1 to 16.4 , results very similar that were found in the current study. Additionally, the turnover of the rabbit is 3 times lower than human, than other advantage is the lower time consuming for complex experiments (24). It was confirmed that rabbit tibia is a useful model to test the different aspects involved with dental implant protocols $(2,14,24)$. Additionally, the tibia rabbit bone is a suitable model to test dental implant integration in different experimental designs and the dynamic indentation model is a very accurate method to test $\mathrm{E}$ and $\mathrm{VHN}$, however the methodological parameters used is this study like to use the metallic recipient for sample embedment and the position of the section of the sample is important to determine the reproducibility of this methodology.

In conclusion, there is no difference between bone mechanical properties, $\mathrm{E}$ and $\mathrm{VHN}$, of high and low profiles of the surround bone to implant. Dynamic microindantion method proved to be highly useful in the characterization of the individual periimplant bone tissue, demonstrating that the computational analysis is pertinent.

\section{Resumo}

0 desempenho clínico de implantes dentais é fortemente definido por princípios biomecânicos. Este trabalho objetivou quantificar a Dureza Vickers (VHN) e módulo de elasticidade (E) do osso periimplantar e discutir parâmetros metodológicos de ensaio dinâmico de indentação. Foram utilizados 10 implantes de corpo cilíndrico com interface cone morse, (Titamax CM; Neodent, Curitiba, PR, Brasil), diâmetro de 3.5 $\mathrm{mm}$ e altura de $7 \mathrm{~mm}$ inseridos em tíbia de coelho recém obtidas após abate dos animais. As propriedades mecânicas foram analisadas usando penetrador dinâmico de microdureza Vickers (CSM Micro-Hardness Tester; CSM Instruments, Peseux, Switzerland) com carga de $200 \mathrm{mN}$ e tempo de penetração de $15 \mathrm{~s}$. Foram feitas 7 indentações no osso cortical na base da rosca $(\mathrm{Br})$ e na ponta da rosca $(\mathrm{Pr})$ na direção perpendicular ao implante, com distância entre elas de $0,08 \mathrm{~mm}$ perpendicular a interface osso implante em direção a superficie esterna. Os dados foram analisados por meio de teste $t-S t u d e n t(P<0,05)$. 0 valores médios e desvio padrão de $E$ (GPa) foram: Br. 16,6 $\pm 1,7 \mathrm{~A}$; Pr. 17,0 $\pm 2,5 \mathrm{~A}$ e VHN (N/mm²): $\mathrm{Br}$. $125,6 \pm 40,8$ A; Pr. 120,1 $\pm 43,7$ A. Não houve diferença significativa entre as propriedades mecânicas avaliadas no osso na base e na ponta da rosca do implante, demonstrando que a caracterização desta estrutura de forma homogênea em análises computacionais é pertinente. 0 método de indentação dinâmica mostrou ser altamente útil na caracterização individualizada do tecido ósseo periimplantar.

\section{Acknowledgements}

This study was supported by the research funding agencies FAPEMIG and CAPES. The authors are grateful to Neodent for full donation of the implants used in this study.

\section{References}

1. Seong WJ, Kim UK, Swift JQ, Heo YC, Hodges JS, Ko CC. Elastic properties and apparent density of human edentulous maxilla and mandible. Int J Oral Maxillofac Surg 2009;38:1088-1093.

2. Seong WJ, Grami S, Jeong SC, Conrad HJ, Hodges JS. Comparison of push-in versus pull-out tests on bone-implant interfaces of rabbit tibia dental implant healing model. Clin Implant Dent Relat Res 2013;15:460-469.

3. Mendonça G, Mendonça DB, Aragão FJ, Cooper LF. Advancing dental implant surface technology--from micron- to nanotopography. Biomaterials 2008;29:3822-3835.

4. Baldassarri M, Bonfante E, Suzuki M, Marin C, Granato R, Tovar N, et al. Mechanical properties of human bone surrounding plateau root form implants retrieved after $0.3-24$ years of function. J Biomed Mater Res B Appl Biomater 2012;100:2015-2021.

5. Coelho PG, Marin C, Granato R, Suzuki M. Histomorphologic analysis of 30 plateau root form implants retrieved after 8 to 13 years in function. A human retrieval study. J Biomed Mater Res B Appl Biomater 2009;91:975-979.

6. Moura CC, Machado JR, Silva MV, Rodrigues DB, Zanetta-Barbosa D, Jimbo $R$, et al. Evaluation of human polymorphonuclear behavior on textured titanium and calcium-phosphate coated surfaces. Biomed Mater 2013;8:035010.

7. Rho JY, Kuhn-Spearing $L$, Zioupos P. Mechanical properties and the hierarchical structure of bone. Med Eng Phys 1998;20:92 -102.

8. Leng $H$, Reyes MJ, Dong XN, Wang X. Effect of age on mechanical properties of the collagen phase in different orientations of human cortical bone. Bon 2013;55:288-291.

9. Balooch M, Habelitz S, Kinney JH, Marshall SJ, Marshall GW. Mechanical properties of mineralized collagen fibrils as influenced by demineralization. J Struct Biol. 2008;162:404-410.

10. Bala $Y$, Depalle B, Douillard $T$, Meille $S$, Clément $P$, Follet $H$, et al.. Respective roles of organic and mineral components of human cortical bone matrix in micromechanical behavior: an instrumented indentation study. J Mech Behav Biomed Mater 2011;4:1473-1482.

11. Brogniez V, Nyssen-Behets $C$, Grégoire $V$, Reychler H, Lengelé B. Implant osseointegration in the irradiated mandible. A comparative study in dogs with a microradiographic and histologic assessment. Clin Oral Implants Res. 2002;13:234-242.

12. Soares EV, Fávaro WJ, Cagnon VH, Bertran CA, Camilli JA. Effects of alcohol and nicotine on the mechanical resistance of bone and bone neoformation around hydroxyapatite implants. J Bone Miner Metab 2010;28:101-107.

13. Mendes VC, Moineddin R, Davies JE. The effect of discrete calcium phosphate nanocrystals on bone-bonding to titanium surfaces. Biomaterials 2007;28:4748-4755.

14. Klokkevold PR, Nishimura RD, Adachi M, Caputo A. Osseointegration enhanced by chemical etching of the titanium surface. A torque removal study in the rabbit. Clin Oral Implants Res 1997;8:442-447.

15. Baker MI, Eberhardt AW, Martin DM, McGwin G, Lemons JE. Bone properties surrounding hydroxyapatite-coated custom osseous integrated dental implants. J Biomed Mater Res B Appl Biomater 2010;95:218-224.

16. Diez-Perez A, Güerri $R$, Nogues $X$, Cáceres $E$, Peña MJ, Mellibovsky $\mathrm{L}$, et al.. Microindentation for in vivo measurement of bone tissue mechanical properties in humans. J Bone Miner Res 2010;25:18771885.

17. Hansma PK, Turner PJ, Fantner GE. Bone diagnostic instrument. Rev Sci Instrum 2006; 075105:77-82.

18. Bicalho AA, Pereira RD, Zanatta RF, Franco SD, Tantbirojn D, Versluis $A$, et al.. Incremental filling technique and composite material--part I: cuspal deformation, bond strength, and physical properties. Oper Dent 2014;39:E71-E82.

19. Bicalho $A A$, Valdivia $A D$, Barreto $B C$, Tantbirojn $D$, Versluis $A$, Soares CJ. Incremental filling technique and composite material--part II: shrinkage and shrinkage stresses. Oper Dent 2014;39:E83-E92.

20. Soons JA, Aernouts J, Dirckx JJ. Elasticity modulus of rabbit middle ear ossicles determined by a novel micro-indentation technique. Hear 
Res 2010;263:33-37.

21. Boettcher HS, Knudsen JC, Andersen PH, Danscher AM. Technical note: Effects of frozen storage on the mechanical properties of the suspensory tissue in the bovine claw. J Dairy Sci 2014;97:29692973.

22. Radovic I, Corciolani G, Magni E, Krstanovic G, Pavlovic V, Vulicevic ZR, et al.. Light transmission through fiber post: the effect on adhesion, elastic modulus and hardness of dual-cure resin cement. Dent Mater 2009;25:837-844.
23. Diefenbeck M, Mückley T, Zankovych $S$, Bossert J, Jandt KD, Schrader $C$, et al.. Freezing of rat tibiae at $-20^{\circ} \mathrm{C}$ does not affect the mechanical properties of intramedullary bone/implant-interface: brief report. Open Orthop J 2011;5:219-222.

24. Clark CL, Strider J, Hall C, Ferguson HW, Armstrong KL, Runner RR, et al.. Distraction osteogenesis in irradiated rabbit mandibles with adjunctive hyperbaric oxygen therapy. J Oral Maxillofac Surg 2006;64:589-593.

Received April 19, 2014 Accepted October 20, 2014 